\title{
La representación social de la muerte a través de la fotografía (Murcia y Jaén, 1870-1902): una historia de la imagen burguesa
}

EMILIO LUIS LARA LÓPEZ

I.E.S. el Valle HUM 768. Universidad de Jaén

\section{RESUMEN}

Durante la segunda mitad del siglo XIX y principios del siglo XX, los muertos eran fotografiados por sus familiares para tener un recuerdo visual de los fallecidos. En esas fotografías los cadáveres parecían dormir, ya que la burguesía construyó una imagen social amable de la muerte. Dichos retratos de muertos reproducían los códigos narrativos visuales implantados por la burguesía en la fotografía decimonónica, pues lo principal era aparentar, ofrecer la imagen de un estatus.

Palabras clave: Fotografía, Burguesía, Muerte, Murcia, Jaén.

\section{SUMMARY}

During the second half of the 19th century and first decades of the 20th century, dead people were photographed by their relatives so that they could keep a visual memory of the deceased. Because the bourgeoisie constructed a gentle social image of death, the people were made to appear in those pictures as though they were only asleep. The pictures thus reproduced the visual narrative codes of the bourgeoisie in $19^{\text {th }}$-century photography, in this case with regard to death. The bourgoisie of the time placed a high value on appearance and on the marks of status.

Key words: Photography, Bourgeoisie, Death, Murcia, Jaen.

Las fotografías realizadas por operadores profesionales en el último tercio del s. XIX y las dos primeras décadas del s. Xx, tienen la virtualidad de poder ser utilizadas como documentos históricos y etnográficos por la cantidad y densidad de información que, convenientemente leída e interpretada, contienen. Esa documentación funciona por tanto como un texto visual (Riego 2001), debiendo el investigador conjuntar las fotografías —en tanto en cuanto documentos fontales (Aróstegui 2001: 388)—, para conformar un corpus documental que posibilite analizar un hecho -que en este caso sería la muerte, o mejor aún, la representación social

RDTP, LX, 2 (2005): 129-147 
de la muerte-, cotejando la seriación de documentos para buscar no sólo analogías formales, sino para rastrear y establecer, transversalmente, la evolución de unos códigos narrativos fotográficos, los cuales son exponentes de unas determinadas mentalidades. Desde hace aproximadamente un lustro, autores de diversas ramas han centrado su atención en las fotografías para, a partir de ellas, realizar sus investigaciones históricas. Merecen ser destacados los trabajos de Peter Burke (1993; 2001) y Bernardo Riego (1994; 1996; 2001) por sus innovadoras propuestas, ya que ambos emplean un utillaje interdisciplinar que permite construir discursos históricos muy sugerentes. E igualmente, es esencial la obra de Pierre Bourdieu (1989; 2003) para analizar la fotografía desde una perspectiva sociológica. Para este artículo hemos seleccionado una gavilla documental cuyas fotografías fueron realizadas en Jaén y en las localidades murcianas de Totana y Lorca, y coincidimos con Carmelo Vega (1999: 137) en el sentido de que al historiador le compete "la reconstrucción de la mirada que hizo posible la aparición de una imagen fotográfica en un determinado momenton.

Ante todo, ha de quedar claro que la denominación de operadores profesionales se refiere sólo a los fotógrafos que, en los ss. XIX y XX, tenían abierto estudio y vivían profesionalmente de la fotografía - si bien algunos eran denominados fotógrafos ambulantes al viajar durante varios meses por diversas provincias para fotografiar y enseñar el oficio en cursillos acelerados (Sánchez Vigil y otros 2001: 196-197)—, debiendo distinguirlos de los aficionados —o amateurs_, que eran aquéllos que, en los albores del siglo veinte, practicaron el arte de Daguerre como bobby, y que en muchos aspectos siguieron caminos plásticos y conceptuales distintos de los marcados por los profesionales decimonónicos (Sánchez Vigil y otros 2001: 214-216). La clientela de estos operadores, básicamente, era la burguesía, que se retratará obteniendo una imagen fidedigna, y además a un precio mucho más asequible que los retratos pictóricos propios de la élite nobiliaria. A partir de la década de 1860 , se producirá una paulatina democratización del hecho fotográfico entre las capas medias y altas, extendiéndose la práctica de retratarse individual y grupalmente, desarrollándose como consecuencia la costumbre de elaborar una memoria gráfica familiar, merced a los álbumes fotográficos, en los que se compartirá espacio, a través del popular formato tarjeta de visita, con retratos de personalidades de la época —entiéndase miembros de la realeza o políticos sobre todo (López Mondéjar 1997: 51-52). Además, las tarjetas de visita facilitaron el paso de la imagen privada a la pública, puesto que no sólamente permitieron dotar de una imagen a una clase social -la burguesía-, sino que, de una manera totalmente nueva hasta entonces, 
posibilitaron ael acercamiento de los rostros ocultos de las celebridades y del poder a las masas, como hicieron posteriormente los medios de comunicación" (Naranjo 2004: 189). Y es que la imagen fotográfica se impone rápidamente porque "viene a llenar funciones que preexistían a su aparición: la solemnización y la eternización de un tiempo importante de la vida colectiva" (Bourdieu 1989: 39).

Esas fotografías tendrán como denominador común la búsqueda de la apariencia social, esto es, representar visualmente la inequívoca pertenencia a una clase: la burguesía, adoptando unas ritualizadas poses y gestos, con una ropa identificativa, diluyéndose así lo individual en lo colectivo; es decir, que el afloramiento - vía fotográfica - de la personalidad propia era algo muy secundario, pues lo que imperaba - desde la mitad del s. XIX hasta los comienzos del xx- era la repetición obsesiva de unos códigos narrativos visuales heredados de la pintura retratística (Freund 1976).

Los operadores profesionales —-sobremanera en la España meridional-, amén de retratar burgueses, fotografiarán las imágenes religiosas que más devoción acumulen en las diferentes localidades, teniendo como destino la piedad doméstica, pues la posesión - a precios harto asequibles- de reproducciones exactas de la figura sagrada original será un motor que reactivará y acrecentará el microcosmos de la religiosidad popular en la sociedad de los cuatro últimos decenios del xIx, al permitir la veneración de una imagen concreta — no ya a través de grabados- en el espacio familiar (Freedberg 1192).

Para fotografiar determinadas tallas religiosas - sobre todo las que se sacan en procesión en Semana Santa-, la técnica existente en el s. XIX -al menos hasta sus estertores - pesaba como una losa a la hora del disparo, pues eran muchas las limitaciones del equipo fotográfico debido a su enorme peso, a requerirse largas exposiciones para impresionar la placa, a la necesidad de sensibilizar dicha placa poco antes de hacer la fotografía, así como a la absoluta dependencia respecto de la luz solar, única fuente lumínica de la que disponían los profesionales. Para adaptarse a esos condicionantes, los operadores, con su voluminoso equipo fotográfico, se desplazaban hasta los lugares de culto de las imágenes sacras, bajándolas de sus altares o capillas para, una vez dispuestas en el suelo de un patio o de la misma calle -zonas donde existía una adecuada iluminación solar-, fotografiarlas (Lara Martín-Portugués y Lara López 2001).

Las fotografías resultantes tendrían unos encuadres heredados de los grabados en madera, realizados durante los siglos XVII, XVIII y XIX, imitando los operadores fotográficos la posición de las tallas religiosas en dichos grabados, apareciendo éstas giradas sustancialmente hacia el hipotético espectador, como es el caso de una placa realizada a la imagen 


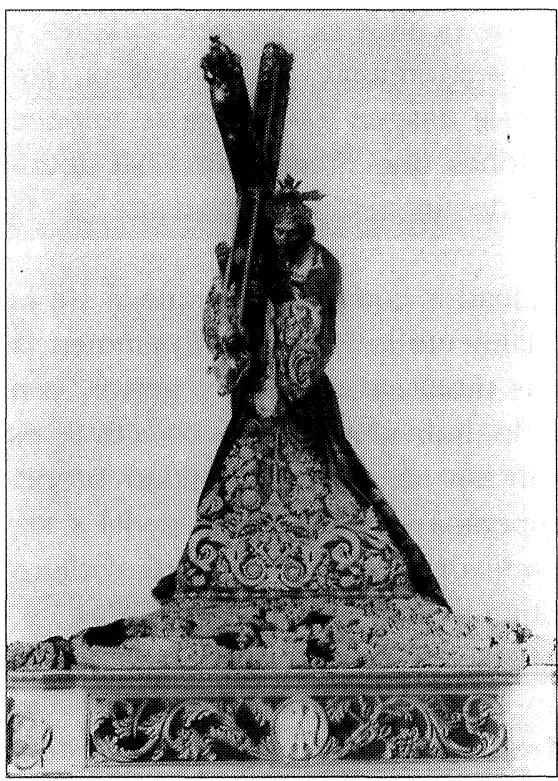

Figura 1.-Manuel Pez. Nuestro Padre Jesús Nazareno. Jaén, 1885. Colección del autor.

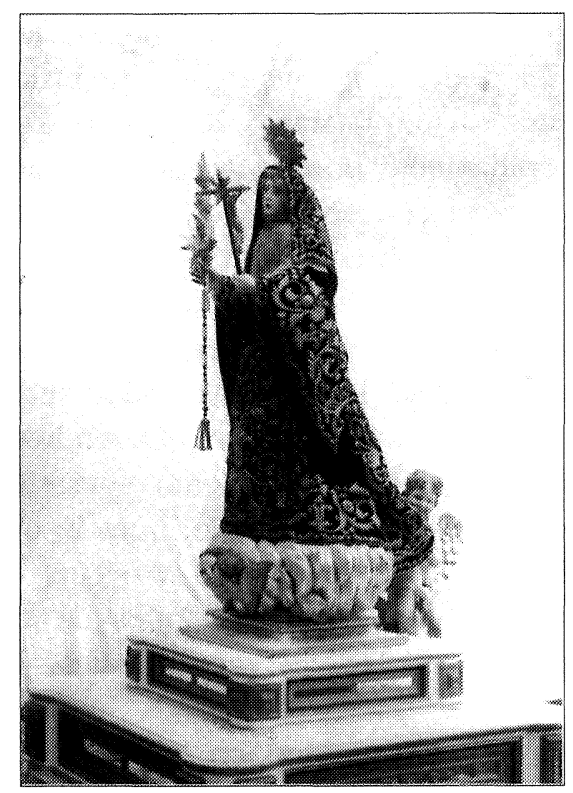

Figura 2.-Manuel Pez. Santa Rita de Casia. Jaén, 1892. Colección del autor.

procesional de Nuestro Padre Jesús Nazareno (figura 1), imagen que centraría la religiosidad popular jiennense durante el s. XIX.

Igualmente, en la ciudad andaluza de Jaén, donde persistía en la segunda mitad del s. xIx el poder de convocatoria de las cofradías, se le hace una fotografía a la talla de Santa Rita de Casia (figura 2), y lo que hemos de destacar en ambos casos es que las esculturas sagradas se nos muestran humanizadas, pues presentan una gestualidad análoga a la de los burgueses: estática, yuxtaponiendo esas fotografías religiosas la función evocadora (sentimental y referencial) a la función icónica (puramente sagrada: rezar ante ellas).

Cuando los miembros de los estratos burgueses acudan, individual o familiarmente, al estudio fotográfico para retratarse, lo harán ataviados con sus mejores trajes, pues insistimos en remarcar que lo que importaba era aparentar, incardinarse socialmente en unas específicas coordenadas, detentar un estatus, y el estudio ejercía como trasunto de las salas de las casas, donde se recibían las visitas de cumplido y se desplegaba la vida social de la burguesía, pues el estudio de la vida cotidiana de las clases acomodadas en el s. XIX permite dar cuenta del lugar primordial que ocupaba la familia burguesa como condicionante ideológico, pero también 


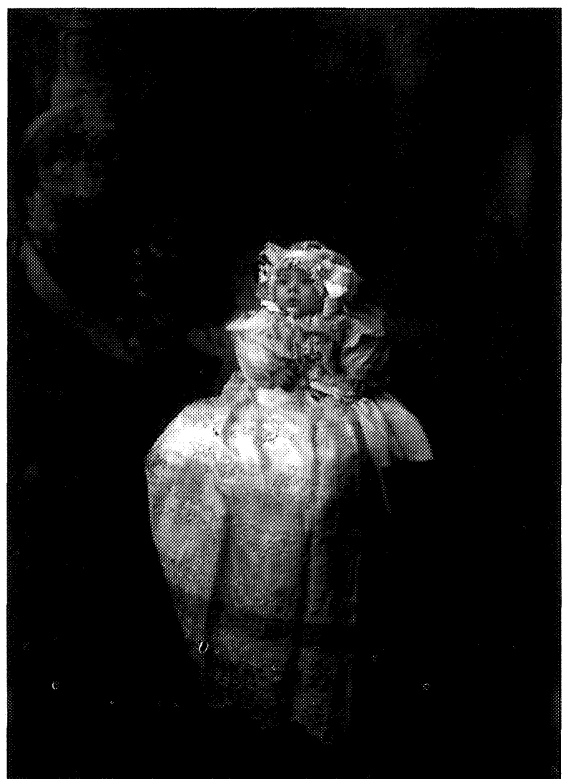

FIGURA 3.-Fernando Navarro. Retrato de niño. Totana (Murcia), hacia 1890. Procedente del libro Fernando Navarro 1867-1944, Murcia: Cehiform, 2002, p. 71. como marco cultural en el que se desenvolvía buena parte de dicha cotidianeidad (Villacorta 1980. Jover $y$ otros 2000).

La burguesía, en virtud de la fotografía, impone unas poses teatralizadas, fruto de la asunción y evolución de unos códigos perceptivos, de unas normas gestuales florecientes en el s. XIX que se injertan en un deseo de idealizar las apariencias y de rechazar la fealdad, en paralelo con los cánones de la pintura académica (Rubio 2001: 22).

Las efigies religiosas, del mismo modo, no serán fotografiadas desnudas - mostrando su estructura de madera-, sino revestidas con sus lujosos ropajes y cubiertas de joyas, lo cual vincula formal y conceptualmente este tipo de fotogra-

fías con los retratos de la burguesía porque, a fin de cuentas, esta clase es la que capitanea la nave de las cofradías pasionistas desde la implantación del régimen liberal en la regencia de María Cristina y el reinado de Isabel II (Lara López 2003).

La eclosión que experimenta el coleccionismo de fotografías del tipo tarjetas de visita desde el decenio de 1860, también denominado cartomanía, aparejó la entrada de la infancia en la memoria fotográfica familiar: los niños —incluso en ocasiones los recién nacidos- son llevados a los estudios fotográficos, para inmortalizarlos solos (figura 3), luciendo un espléndido traje de cristianar —el ritual del retrato se ligó al rito de los sacramentos-, o bien acompañados de su padre (figura 4), adoleciendo ambas figuras de un acusado hieratismo por mor de la técnica -hacia 1870-, ya que las cámaras aún requerían de varios segundos de exposición para impresionar convenientemente la placa, y cualquier movimiento, por leve que fuera, echaba a perder la foto, saliendo las personas movidas, borrosas, con un característico efecto fantasmal en la imagen. De todos modos, la composición padre e hija (figura 4) semeja a un ventrílocuo con su muñeco.

El ya mencionado rito del bautizo brindará la oportunidad, conforme 


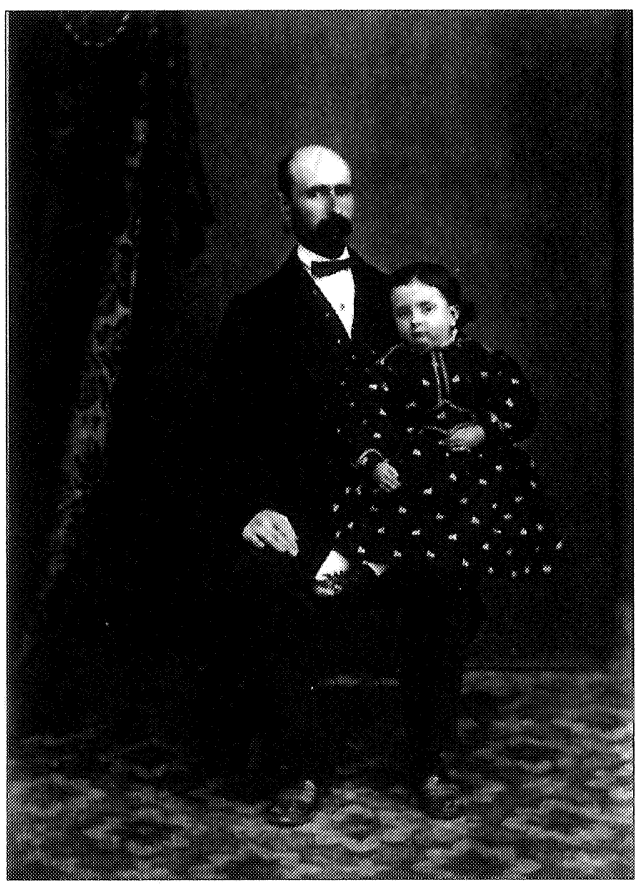

FIgURA 4.-Higinio Montalvo. Retrato de padre e hija. Jaén, hacia 1870. Colección del autor. transcurran las tres últimas décadas del s. XIX, de fotografiarse familiarmente (figura 5), ocupando el individuo que ejerce como patriarca el centro visual de la fotografía —en la cual aparece la familia extensa-, siguiendo así las pautas habituales en las escenas grupales pictóricas, pues es fundamental recordar una y otra vez la ligazón establecida por la fotografía decimonónica respecto a la pintura (Haskell 1994; Sougez 1994; Scharf 1994).

En otro ejemplo de ese tenor (figura 6), la familia -nuclear - acude al estudio, sentándose el padre en una mecedora mientras acuna en sus brazos al niño de pecho. Los

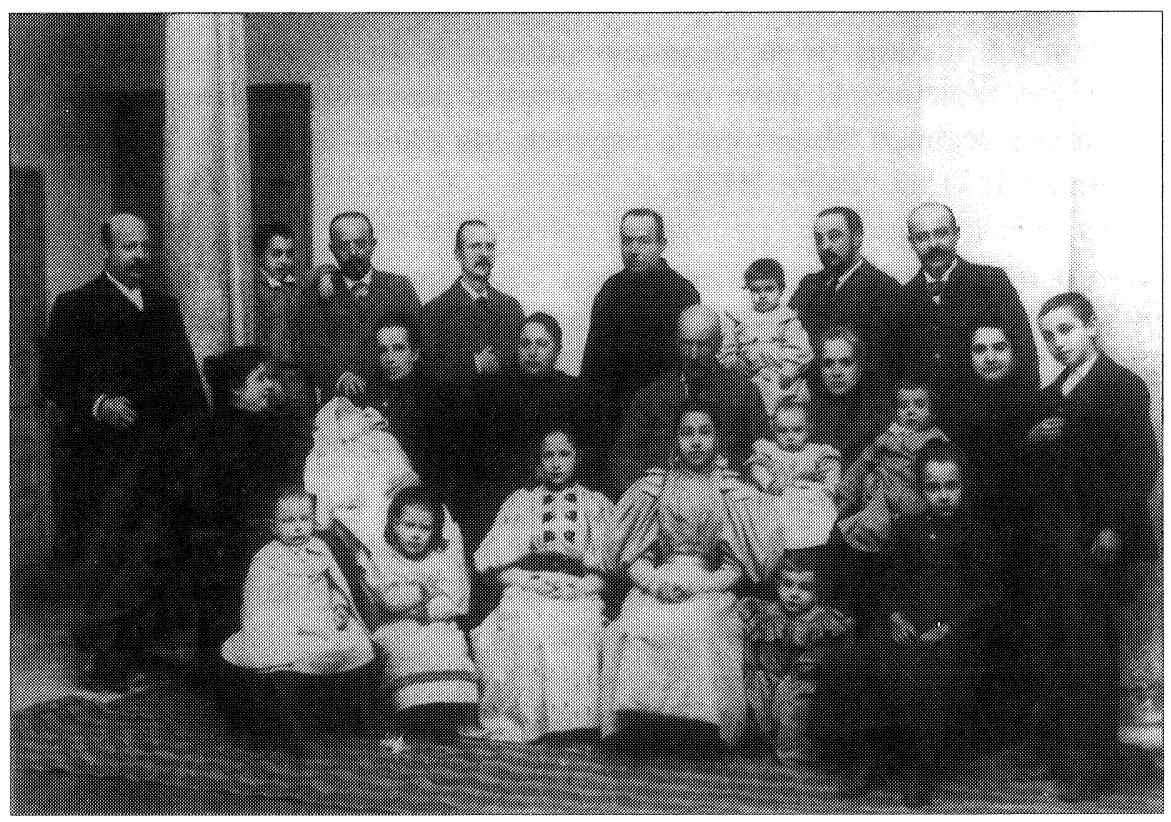

Figura 5. Anónimo. Retrato de familia con motivo de un bautizo. Jaén, 1890 Colección del autor. 


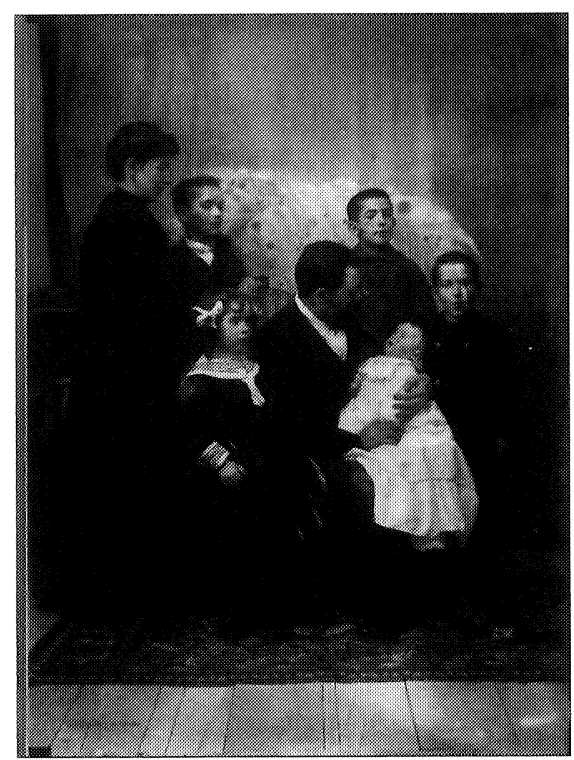

FiguRA 6.-Fernando Navarro. Autorretrato con familia. Totana (Murcia), hacia 1900. Procedente del libro Fernando Navarro 1867-1944, Murcia: Cehiform, 2002, p. 6. hijos de la alta burguesía (figura 7), acompañados de dos jóvenes familiares, se retratan a principios del siglo $\mathrm{xx}$ adoptando poses afectadas, imitando a los mayores.

En las comunidades rurales - ya del s. $\mathrm{xx}$-, se repiten básicamente los esquemas visuales de la fotografía del diecinueve, pues en un retrato de grupo (figura 8) los miembros con más peso específico se sitúan hacia el centro de la foto; los niños entran con derecho propio en ese testimonio gráfico, y los más pequeños son aupados, sostenidos en brazos.

$\mathrm{Y}$ en otra comunidad, esta vez de frailes (figura 9), dos capuchinos componen un cuadro plástico epígono del pictorialismo, una corriente fotográfica muy permeada de la pin-

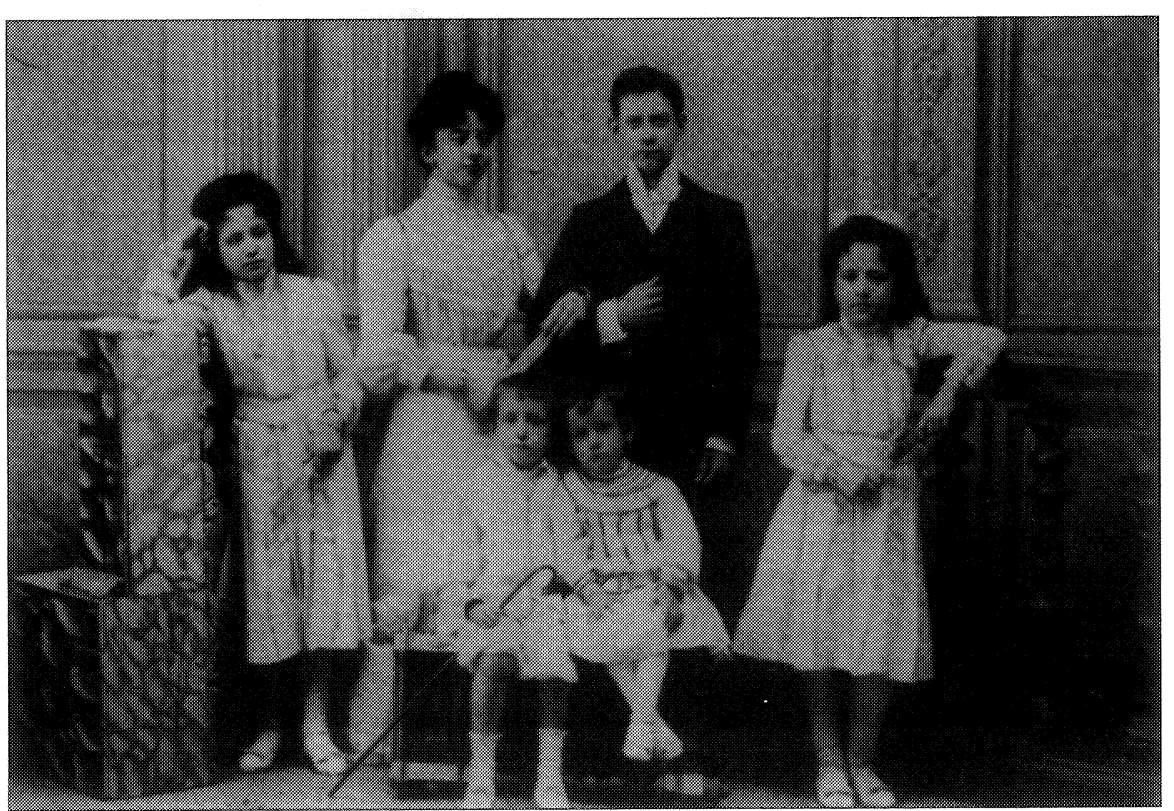

Figura 7.-Ángel Martos. Retrato de hermanos. Jaén, 1902. Colección del autor. 


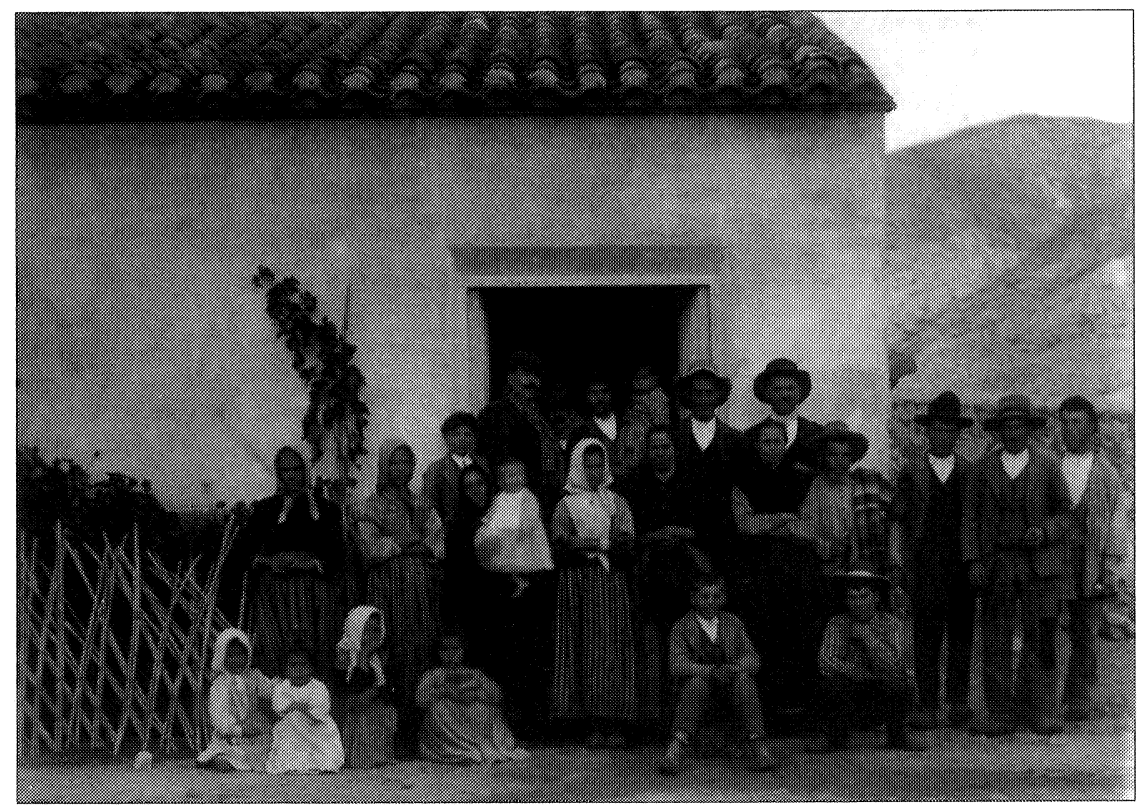

Figura 8.-Fernando Navarro. Retrato de grupo. Totana (Murcia), hacia 1901 Procedente del libro Fernando Navarro 1867-1944, Murcia: Cehiform, 2002, p. 37.

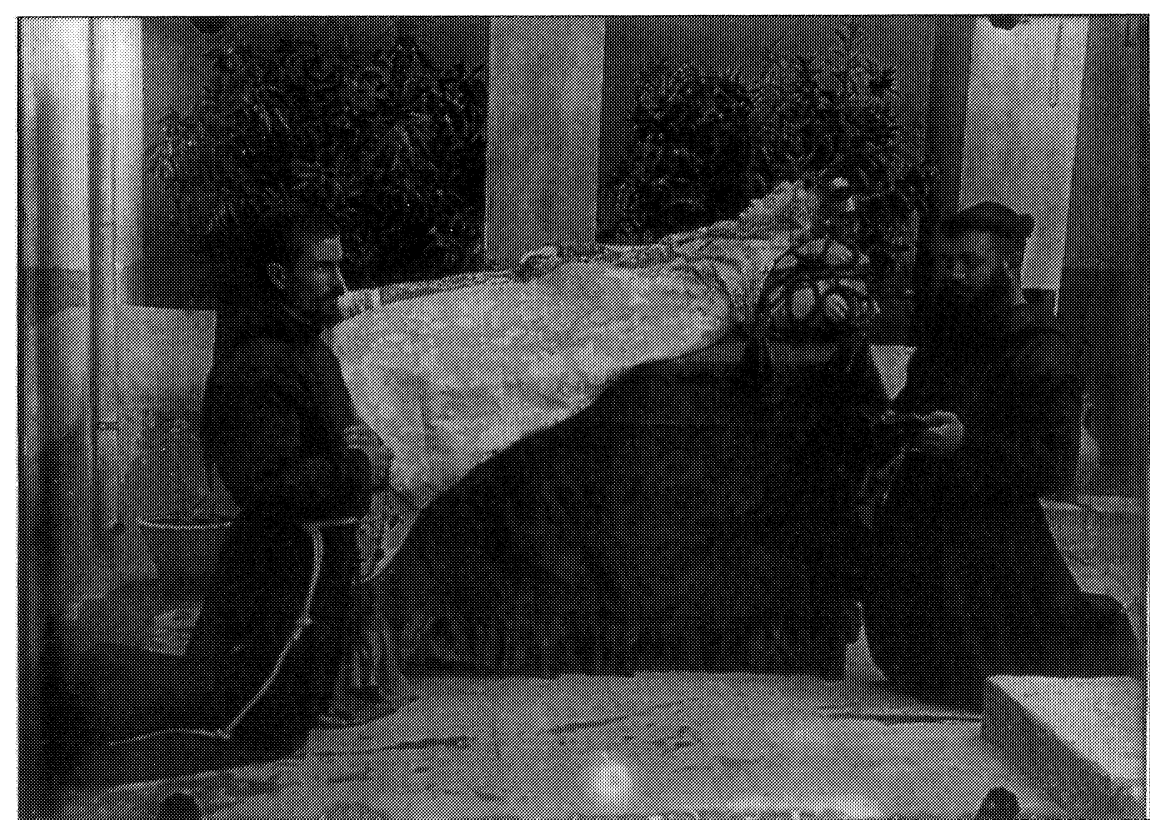

FIGURA 9.-Fernando Navarro. Frailes capuchinos velando la imagen de la Dormición de la Virgen. Totana (Murcia), hacia 1895. Procedente del libro Fernando Navarro 1867-1944, Murcia: Cehiform, 2002, p. 12. 
tura impresionista y de los cuadros de historia, tan en boga en el s. XIX. Pues bien, los dos frailes, en una composición preparada hasta el último detalle por el operador, aparentan rezar/meditar ante una imagen de la Dormición de la Virgen, una advocación muy popular en las cofradías desde el Barroco y que representa a María, una vez muerta, en espera a que su cuerpo sea recogido por los ángeles para iniciar su Asunción a los cielos. Lo peculiar de esa fotografía es que supone una traslación al campo religioso de los valores fotográficos impuestos por la burguesía, pues la estancia simula un estudio en el que todo está dispuesto estratégicamente: las ventanas del fondo con la vegetación son un paralelismo de los forillos, los fondos pintados que aparecen en los retratos de la burguesía para, a la manera de un decorado teatral, dar una ilusoria sensación de naturalismo (figuras 3, 6 y 7); la efigie mariana reposa sobre un catafalco, es decir, el equivalente al atrezzo, al mobiliario y panoplia de objetos que circulaban en los estudios (figuras 4, 6 y 7); y los frailes acompañan una escultura religiosa durmiente, nada trágica, que desprende placidez y serenidad, significando el morir como un dulce tránsito.

Todo esto viene a colación por la enorme influencia que en las mentalidades del s. XIX ejercía el catolicismo, con sus rituales de religiosidad popular que tanto peso tenían en España (Domínguez 1999), ya que se mantiene una idea negativa de la condición humana, herencia de la concepción romántica del catolicismo al pervivir la relación pecado-castigo no sólo desde la perspectiva individual sino social. En consecuencia en el ambiente de la sociedad decimonónica flotaba también una presencia viva y religiosa de la buena muerte, según la expresión acuñada en el $\mathrm{s}$. XVII por los místicos hispanos.

Esta idea del buen morir, de la muerte como un letargo eterno, que se evidencia en la fotografía de los frailes capuchinos (figura 9), es un eje vertebrador del concepto de la muerte en la burguesía, entrelazándose esto con la necesidad imperiosa de retener la memoria, de aprehender visualmente a un ser fallecido. Este hilo conductor sería: las fotografías de imágenes religiosas (figuras 1 y 2) funcionan como iconos, mostrándose las efigies sacras humanizadas, mas nunca como obras artísticas; los burgueses se hacen retratar para saciar su sed de apariencia social, pues la fotografía es el sustituto - barato- de la pintura, y a este carácter áulico del retrato fotográfico hay que sumar el gusto por coleccionar fotos, naciendo los álbumes, subyaciendo en dichas fotografías - del tipo tarjetas de visita - un poso icónico nada despreciable, pues se empieza a rendir culto gráfico a la memoria de los familiares y deudos desaparecidos, porque gracias a la fotografía, la imagen de una persona no se desvanece con el paso del tiempo, reactivándose y reforzándose con su contemplación el 
recuerdo visual del finado. Si no había fotografías de esa persona en vida, se la retrataba muerta.

Las tarjetas de visita actuarán como un revival de la nostalgia, que ahora puede aglutinar a los parientes desconocidos, a los difuntos y a los recién nacidos, de modo que los álbumes fotográficos tienen una función nucleadora de la memoria al socaire de la nueva sociedad que, a lo largo del s. XIX, se estaba construyendo. Los retratos contenidos en el álbum fotográfico reforzaban los lazos familiares en un momento en que la dinámica social (revolución industrial, movimientos migratorios, debilitamiento de las tradiciones, etc.) empieza a erosionar dichos lazos. Las ventajas de la pequeña tarjeta - fotografía del tipo tarjeta de visita- para su intercambio por correo ayudaron a mantener la sensación de unidad (visual) en el seno de la familia disgregada (Rubio 2001: 23).

Los retratos de difuntos fueron una modalidad muy en boga en la España del s. XIX, manteniéndose por parte de algunos operadores profesionales hasta aproximadamente 1918, coincidiendo con el final de la Gran Guerra. El desarrollo de la fotografía hizo de la muerte un hecho más igualitario, permitiendo que el arte ritual del retrato de difuntos adoptase nuevas formas de representación popular (López Mondéjar 1997: 71), y este afán de retener la memoria visual de los difuntos se plasmaría en la práctica de integrar los retratos de los miembros de la familia muertos en las hojas del álbum fotográfico.

La fotografía retratística mortuoria no se limitó a adultos, sino que también, y muy especialmente, se enfocó hacia la infancia, pues las aún elevadas tasas de mortalidad infantil motivaban que, tras el óbito de un hijo, sus padres y hermanos mayores quisieran disponer con celeridad de un retrato suyo. Ya se trate de retratos de personas mayores o de niños, los mismos fotógrafos que estaban habituados a retratar exequias y capillas ardientes, fotografiaban difuntos según unos interiorizados códigos narrativos visuales que no eran sino estereotipos sociales, de manera que los cadáveres aparentaban dormir.

En efecto, el cadáver era amortajado con sus ropas de uso cotidiano o con uno de sus mejores trajes, y a veces era conducido al estudio fotográfico. Una vez allí, el operador profesional componía la escena como si se tratase de un retrato que condensase todos los estereotipos burgueses, de modo que el muerto pareciese dar una cabezada, echar una confortable siesta, esto es, enmascarar la muerte por medio de una careta amable, muy en la línea del decoro burgués. Así se entiende que un padre sostenga entre sus piernas el cadáver de su hijo (figura 10), explicitándose ahí unos códigos narrativos fotográficos (figura 4) empleados en la retratística de la segunda mitad del s. XIX, puesto que ambas fotografías tienen una datación similar -hacia 1870. 


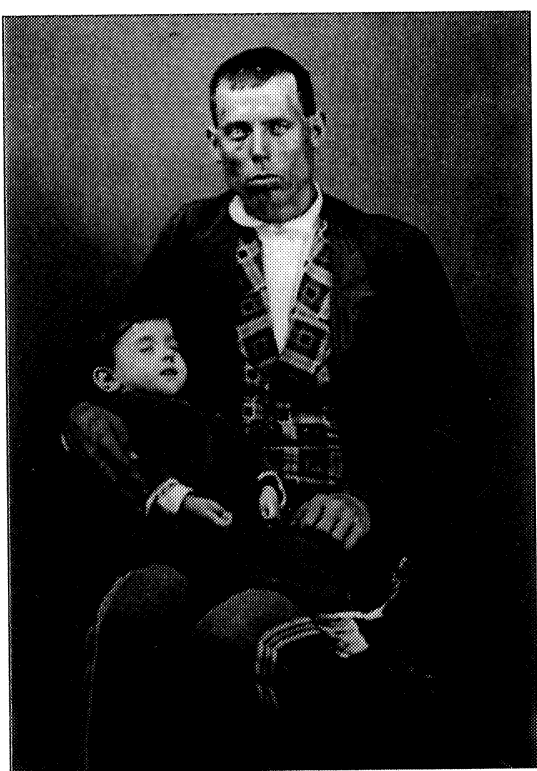

FIGURA 10.-José Rodrigo. Padre con su hijo muerto. Lorca (Murcia), 1870. Archivo Municipal de Lorca.

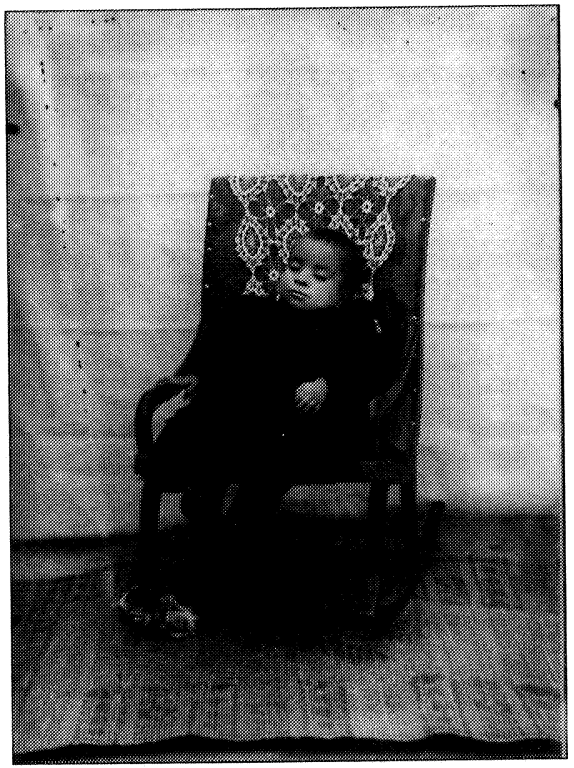

FIGURA 11.-Fernando Navarro. Retrato de niña muerta. Totana (Murcia), hacia 1890. Procedente del libro

Fernando Navarro 1867-1944, Murcia: Cehiform, 2002, p. 101

Otras veces el niño muerto - con vestido enlutado- aparenta estar dormido en una mecedora (figura 11), objeto que ha sido sacado de la casa, porque el operador se desplazó al domicilio del niño fallecido, como demuestra el suelo de tierra apisonada, el esterillo y la sábana blanca que sirve de fondo neutro y hace las veces de improvisado forillo. $\mathrm{Y}$ esta escena tan burguesa de la siesta en una mecedora —en el respaldo hay un tapete de ganchillo-, ya la habíamos visto antes en una escena familiar (figura 6).

Entre los operadores que frecuentaron esta modalidad retratística, sobresale Fernando Navarro, fotógrafo que desplegó su actividad profesional en Totana (Murcia), su localidad natal, en las primeras décadas del s. Xx (López Martínez 2002). Fernando Navarro optará por trasladar sus bártulos fotográficos a las casas de los fenecidos para realizar in situ el retrato —en un patio-, pues sólo se necesitaba, como ya se dijo, una sábana blanca como fondo y luz solar. Este profesional trasvasará los códigos narrativos fotográficos burgueses a los retratos de difuntos, como cuando unas hermanas rodean al niño recién nacido muerto (figura 12), metido en su cuna/caja recubierta con una rica tela, con traje de cristianar, 


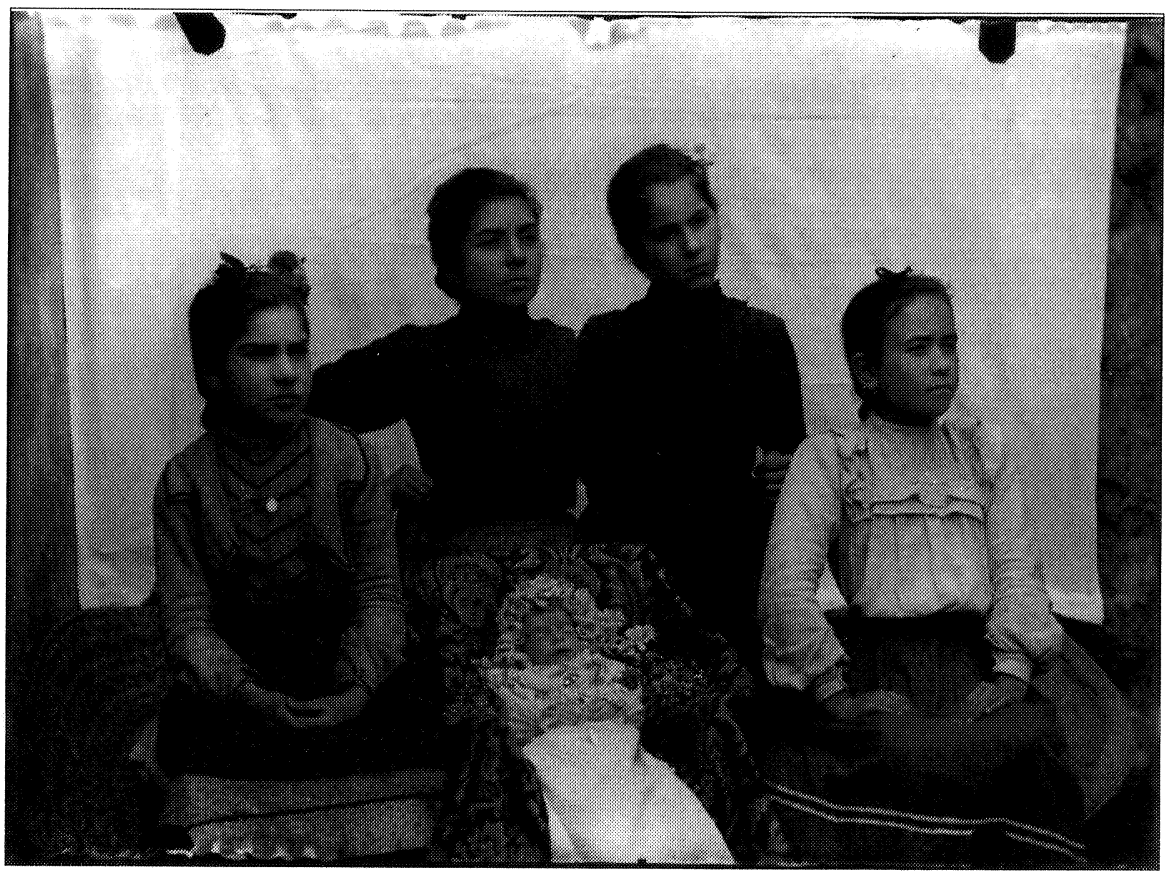

FIGURA 12.-Fernando Navarro. Retrato con hermano muerto. Totana (Murcia), hacia 1900. Procedente del libro Fernando Navarro 1867-1944, Murcia: Cehiform, 2002, p. 104.

remedando escenas pletóricas de vida que hemos analizado con anterioridad (figura 6).

O como cuando una mujer (figura 13) es retratada sentada - la silla permanece prácticamente oculta-, porque los retratos sedentes suponen una deferencia hacia la persona (figuras 4, 5, 6, 10 y 14). El esquema de persona - hombre o mujer- sosteniendo en brazos a un niño se repite (figura 14), echando por encima del sillón una tela para recordar el confort del salón, al ser el sofá el mueble que, por su efecto enriquecedor, es signo del progreso burgués, ya que en el siglo XIX los tapiceros son los auténticos decoradores de interiores, pues estos artesanos definen y determinan el aspecto y forma de utilizar las habitaciones, y por tanto, la disposición de los muebles (Ruiz Zapata 2000: 55).

La identificación del buen morir con un letargo eterno, se materializa gráficamente (foto 15), estando de pie dos niños junto al hermano muerto que reposa - hacia 1910 - en un diván/cama, repitiendo el operador, Fernando Navarro, el esquema formal y conceptual experimentado con anterioridad -1909- (figura 9): los dos frailes son esta vez los hermanos, trocándose la efigie de la Dormición de la Virgen por el cuerpo inerte 


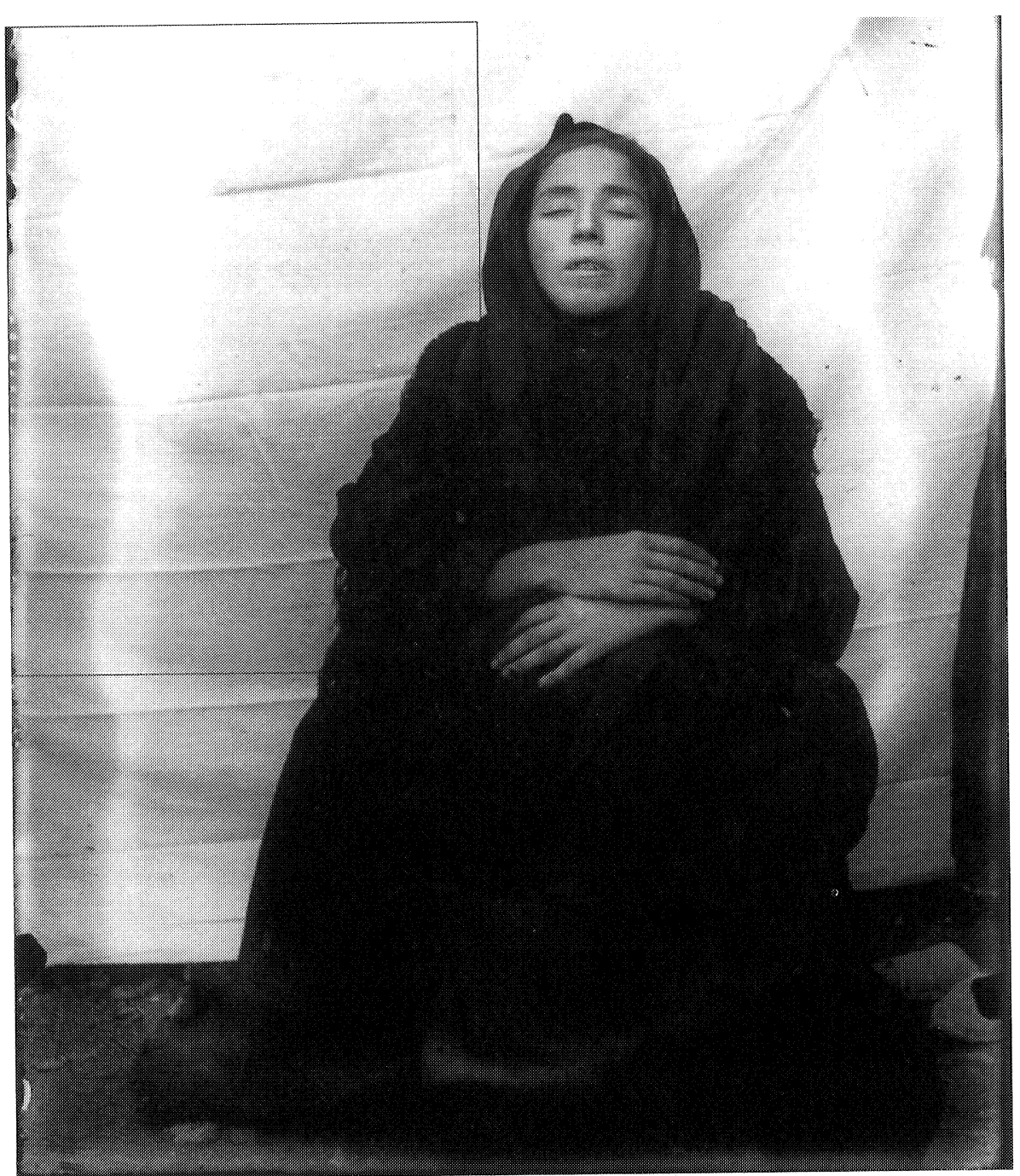

FIGURA 13.-Fernando Navarro. Retrato de difunta. Totana (Murcia), hacia 1898. Procedente del libro Fernando Navarro 1867-1944, Murcia: Cehiform, 2002, p. 105.

del niño, y el túmulo de la imagen mariana por el diván/cama. Además, ambos ejemplos (figuras 9 y 15) albergarían una finalidad icónica, religiosa una y memorialista la otra.

Esta penetración de la fotografía religiosa en la profana, o mejor dicho, este aburguesamiento de la simbología religiosa, cristaliza en un retrato de la jiennense marquesa de Blanco Hermoso, que será retratada de 


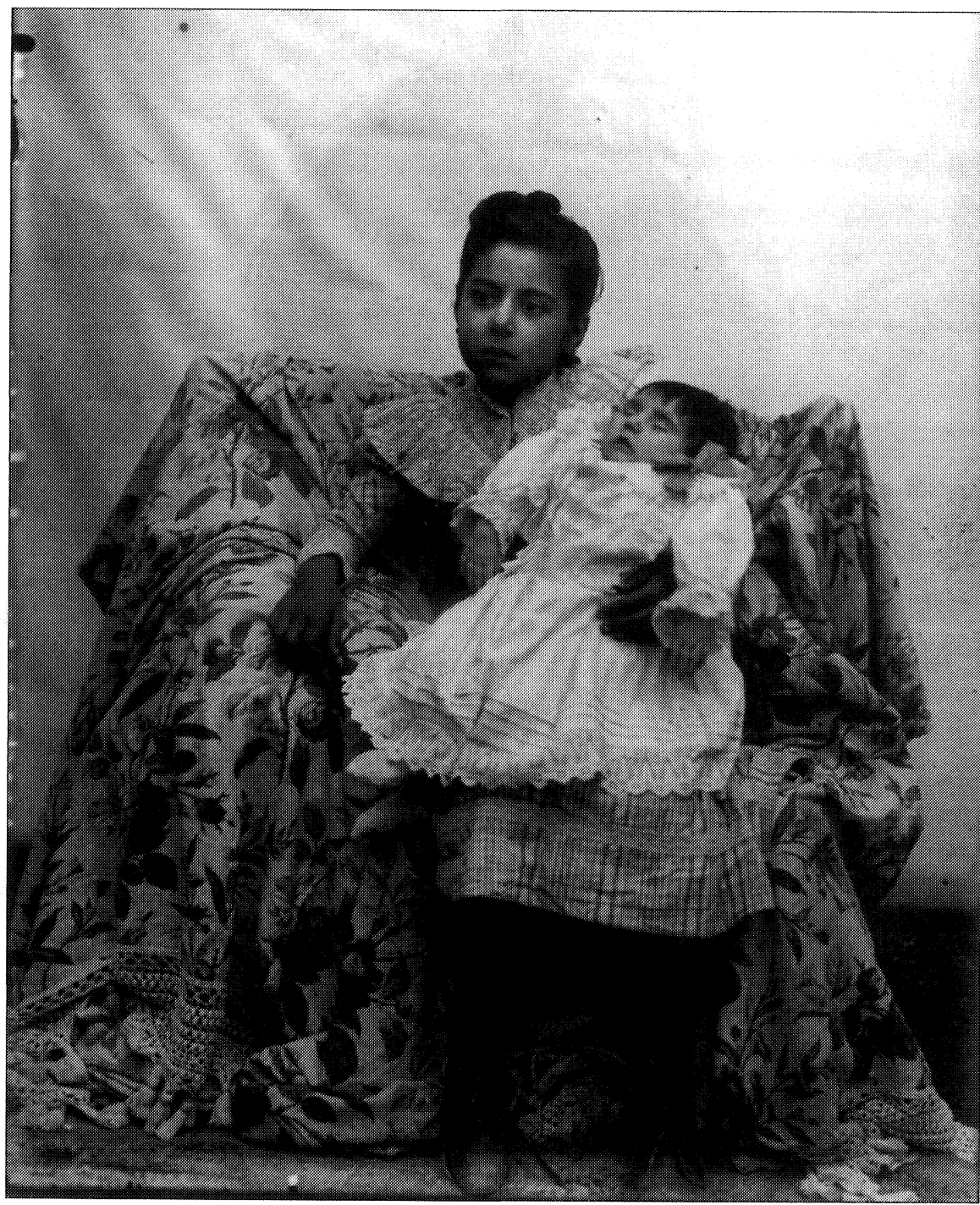

FiguRA 14.-Fernando Navarro. Retrato con hermana muerta. Totana (Murcia), hacia 1898. Procedente del libro Fernando Navarro 1867-1944, Murcia: Cehiform, 2002, p. 102.

cuerpo presente (figura 16) con un hábito de monja -una práctica muy seguida por las élites aristocráticas decimonónicas en una sociedad fuertemente católica-, introduciéndose en el velatorio aristocrático unos elementos iconográficos prestados de la iconografía religiosa como ya hemos repetido.

La asunción por parte de los códigos narrativos visuales (fotográficos) 


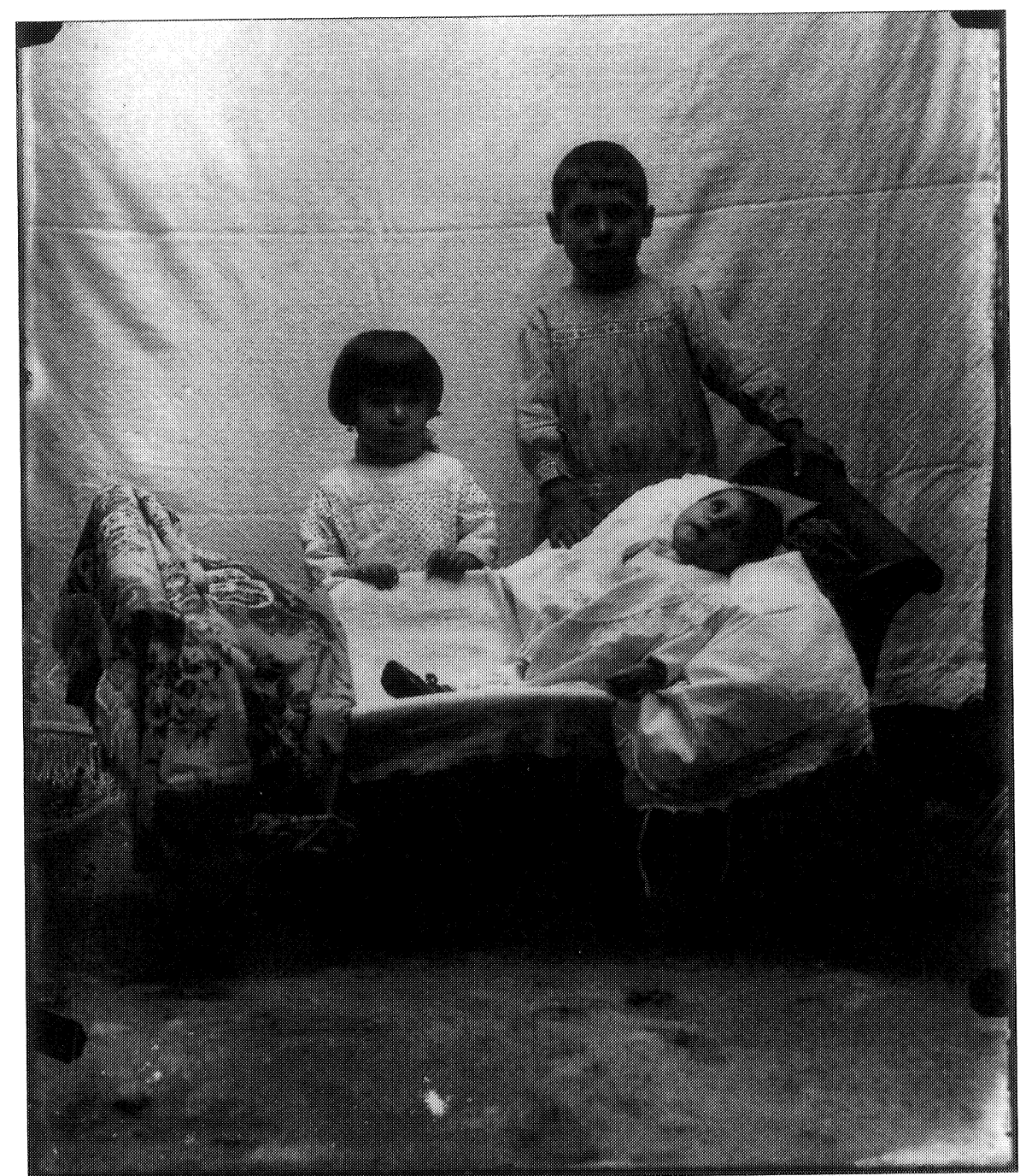

FIGURA 15.-Fernando Navarro. Retrato con hermano muerto. Totana (Murcia), hacia 1902. Procedente del libro Fernando Navarro 1867-1944, Murcia: Cehiform, 2002, p. 103.

del lenguaje narrativo del arte religioso, se galvaniza en un abigarrado retrato grupal (figura 17), obra de Fernando Navarro. La fotografía se concibe como una auténtica puesta en escena de la muerte en familia, como una especie de solemne altar de la muerte, donde la hornacina central viene representada por el ataúd con la mujer fallecida, formando las calles laterales y el ático de un supuesto retablo los familiares condolidos, 


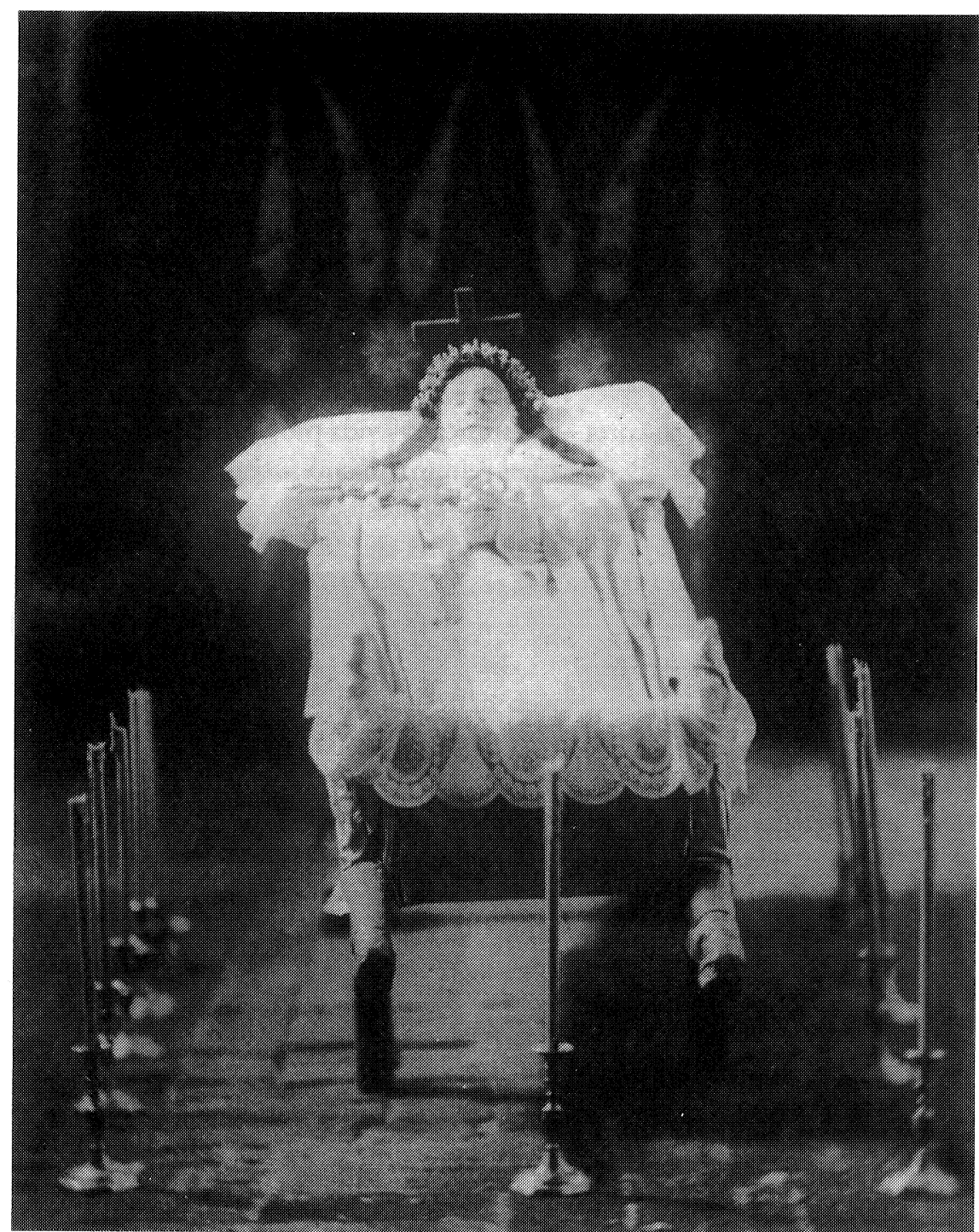

Figura 16. Joaquín Martos. Retrato del cadáver de Ana Josefa López

de Mendoza, Marquesa de Blancohermoso. Jaén, 1878. Colección del autor.

mientras la predela estaría representada por las mujeres postradas de hinojos, como dispuestas a rezar un rosario. Esta composición fotográfica no hace sino trasladar los esquemas conceptuales de algunos pasos de misterio de la Semana Santa andaluza conformados en la segunda mitad del s. XIX.

En ese retrato de adensada luctuosidad (figura 17), la nota discordan- 


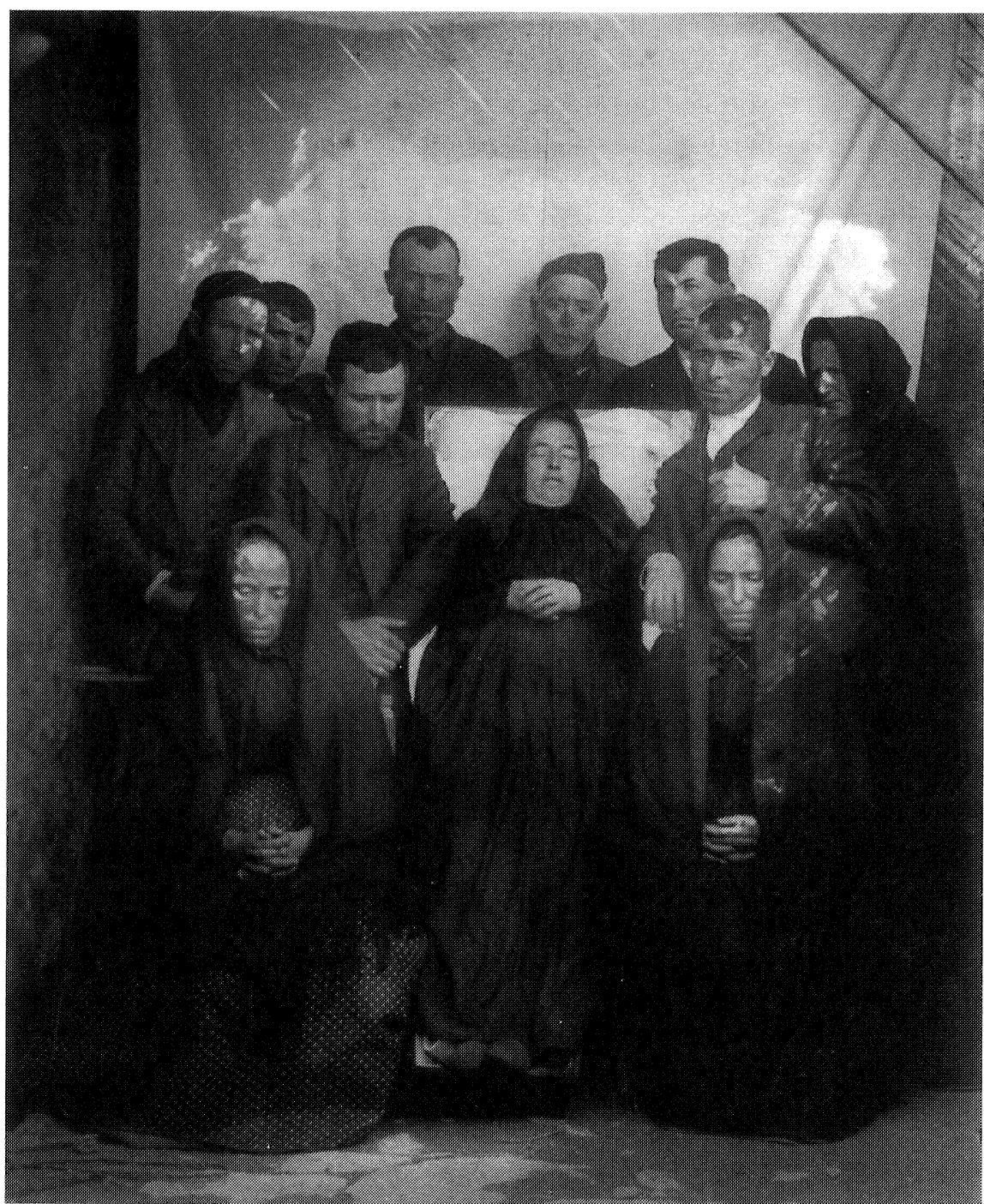

Figura 17. Fernando Navarro. Retrato de grupo con muerta. Totana (Murcia), hacia 1900. Procedente del libro Fernando Navarro 1867-1944, Murcia: Cehiform, 2002, p. 107.

te entre tanta pena la pone el hombre que se apoya distraídamente en el ataúd - alzado-, mientras se lleva la otra mano al chaleco, componiendo un característico gesto burgués - de satisfacción personal- que hemos visto antes (figuras 5 y 7). Por lo demás, asistimos al ritornello en el que se identifica muerte con dormición, estando expuesto el cuerpo en una cama/caja/túmulo (figuras 9, 12, 15, 16 y 17). 
Como conclusión, las fotografías constituyen una fuente histórica de primera magnitud para comprender cómo, durante el último tramo del s. XIX, las pautas sociales burguesas y la representación visual de su estatus a través de los retratos fotográficos se trasvasaron a la retratística de difuntos, lo que motivó una especialidad fotográfica morbosa a nuestros ojos y sensibilidad actuales, pero que en su contexto original significaban el recuerdo de una persona fallecida —quizá el único recordatorio visual que existía de esa persona-, y esta práctica estaba transversalizada por el interés en que se construyese una representación social de la muerte, acorde con el decoro burgués, pues ésta quedaba camuflada por un trasunto de sueño. En estas fotografías, los cadáveres aparentaban -y esto es lo primordial- dormir plácidamente en una estancia de la casa, como si fueran a despertar de un momento a otro.

\section{BiBLIOGRAFÍA}

Aponte marín, Ángel y Juan ANTONio López Cordero. 2000. El miedo en Jaén. Jaén: Diputación Provincial de Jaén.

ARÓSTEGUI, JULIO. 2001. La investigación histórica: teoría y método. Barcelona: Crítica. BourdieU, Pierre (comp.). 1989. La fotografía. Un arte intermedio. México: Nueva Imagen.

- 2003. Un arte medio: ensayo sobre los usos sociales de la fotografía. Barcelona: Gustavo Gili.

BURKE, PETER. 1993. "Obertura: la nueva historia, su pasado y su futuro", en P. Burke (ed.), Formas de hacer bistoria: 11-37. Madrid: Alianza.

-. 2001. Visto y no visto. El uso de la imagen como documento bistórico. Barcelona: Crítica.

DOMÍNGUEZ LEÓN, JOSÉ. 1999. "Religiosidad popular y anticlericalismo en la Andalucía del siglo XIX. Aproximación metodológican, en S. Rodríguez Becerra (coord.), Religión y Cultura, volumen 2: 517-531. Sevilla: Fundación Machado.

FREEDBERG, DAVID. 1992. El poder de las imágenes. Madrid: Cátedra.

FREUND, GISELE. 1976. La fotografía como documento social. Barcelona, Gustavo Gili.

HASKELl, FRANCIS. 1994. La historia y sus imágenes. El arte y la interpretación del pasado. Madrid: Alianza.

Jover Zamora, José María, Guadalupe GÓmez-Ferrer, y Juan Pablo Fusi AizPúrua. 2000. España: sociedad, politica y civilización (siglos XIX-XX). Madrid: Areté.

LARA LÓPEZ, EMILIO LUIS. 2003. La religiosidad popular pasionista contemporánea (Jaén, 1859-1978). Una historia a través de la fotografía como fuente documental. Jaén: Instituto de Estudios Giennenses.

Lara Martín-Portugués, Isidoro y LARA López, Emilio luis. La memoria en sepia. Historia de la fotografia jiennense desde los orígenes hasta 1920. Jaén: Instituto de Estudios Giennenses, 2001.

LóPez Martínez, José Francisco. 2002. Fernando Navarro, 1867-1944. Murcia: Cehiform.

LÓPEZ MONDÉJAR, PUBLIO. 1997. Historia de la fotografía en España. Barcelona: Lunwerg. 
NARANJO, JuAn. 2004. "Las tarjetas de visita. Del retrato privado a la imagen pública", en De París a Cádiz. Calotipia y colodión: 188-197. Barcelona: Museo Nacional d'Art de Catalunya.

Riego, Bernardo. 1994. "De la Fotohistoria a la Historia con la Fotografía". Fotografía y métodos bistóricos: 11-37. Santander, Universidad de Cantabria/Universidad de La Laguna.

—. 1996. "La historiografía española y los debates sobre la fotografía como fuente histórica". Ayer 24: 91-111.

- 2001. La construcción social de la realidad a través de la fotografía y el grabado informativo en la España del siglo XIX. Santander: Universidad de Cantabria.

Rubio ARAGONÉs, JuAN CARLOS. 2001. "Retrato y paisaje en la fotografía del siglo XIX. Colecciones privadas de Madrid. Retrato y paisaje en la fotografía del siglo XIX. Colecciones privadas de Madrid: 15-34. Madrid: Fundación Telefónica.

Ruiz ZAPATA, ANA MARÍA. 2000. Itinerarios. Los interiores domésticos. Madrid: Museo Thyssen-Bornemisza.

Sánchez Vigil, Juan Miguel, Kurtz, Gerardo, Fontcuberta, Joan y Ortega, isabel. 2001. La Fotografía en España. De los orígenes al siglo XXI. volumen XLVII de Summa Artis. Madrid: Espasa Calpe.

SCHARF, AARON. 1994. Arte y fotografia. Madrid: Alianza.

SOUgez, MARIE-Loup. 1994. Historia de la fotografía. Madrid: Cátedra.

VEGA, CARMELO. 1999. "Divergencias, correspondencias: extravíos de la fotografía en la Historia del Arte", en Historia de la Fotografía del siglo XIX en España: una revisión metodológica: 125-139. Pamplona: Gobierno de Navarra.

VILlACORTA BAÑos, FRANCISCO. 1980. Burguesía y cultura. Los intelectuales españoles en la Sociedad Liberal 1808-1931. Madrid: Siglo XXI Editores. 